\title{
Partitioning the effects of environmental and spatial heterogeneity on distribution of plant diversity in the Yellow River Estuary
}

\author{
YUAN Xiu $^{1,2}$, MA KeMing ${ }^{1 *} \&$ WANG De ${ }^{3}$ \\ ${ }^{1}$ State Key Laboratory of Urban \& Regional Ecology, Research Center for Eco-Environmental Sciences, Chinese Academy of Sciences, Beijing \\ 100085, China; \\ ${ }^{2}$ Graduate University of Chinese Academy of Sciences, Beijing 100049, China; \\ ${ }^{3}$ Yantai Institute of Coastal Zone, Chinese Academy of Sciences, Yantai 264003, China
}

Received March 12, 2012; accepted April 25, 2012

\begin{abstract}
For successful conservation and restoration of biodiversity, it is important to understand how diversity is regulated. In the ecological research community, a current topic of interest is how much of the variation in plant species richness and composition is explained by environmental variation (niche-based model), relative to spatial processes (neutral theory). The Yellow River Estuary (YRE) is a newly formed and fragile wetland ecosystem influenced by both the Yellow River and Bohai Bay. Here, we applied variance partitioning techniques to assess the relative effects of spatial and environmental variables on species richness and composition in the YRE. We also conducted a species indicator analysis to identify characteristic species for three subestuaries within the YRE. Partial redundancy analysis showed that the variations in species richness and composition were explained by both environmental and spatial factors. The majority of explained variation in species richness and composition was attributable to local environmental factors. Among the environmental variables, soil salinity made the greatest contribution to species abundance and composition. Soil salinity was the most important factor in the Diaokou subestuary, while soil moisture was the most important factor influencing species richness in the Qingshui and Chahe subestuaries. The combined effects of soil salinity and moisture determined species richness and composition in the wetlands. These results increase our understanding of the organization and assembly of estuarine plant communities.
\end{abstract}

environment, spatial variation, species composition, species richness, variation partitioning

Citation: Yuan X, Ma K M, Wang D. Partitioning the effects of environmental and spatial heterogeneity on distribution of plant diversity in the Yellow River Estuary. Sci China Life Sci, 2012, 55: 542-550, doi: 10.1007/s11427-012-4338-3

Species diversity is a major determinant of stability, primary productivity, nutrient dynamics, and other ecosystem traits [1]. It is also a key concept for understanding the functioning of ecosystems, biodiversity conservation, and ecosystem management [2]. It is important to identify the main factors controlling species richness (alpha diversity) and species composition (beta diversity) to accurately predict their effects on natural communities and ecosystems. Factors influencing patterns of diversity are usually a com-

*Corresponding author (email: mkm@ @rcees.ac.cn) bination of environmental and geographic variables [3], although their relative importance varies with the taxonomic group, taxonomic level, spatial scale, and geographic region of each species $[4,5]$. Traditionally, it was thought that local patterns of diversity resulted from differences in environmental factors and ecological niches [6]. If environmental variables are spatially autocorrelated, then the pattern of environmental variables will induce spatial dependence in diversity pattern $[7,8]$. However, a recent study showed that the spatial autocorrelation of species abundance is often due to dispersal constraints, competition, or aggregation on 
small to intermediate scales [7]. This means that the spatial distribution of species may also arise by neutral mechanisms [9]. The relative role of space and environment as determinants of biodiversity patterns is an important area of interest in ecology at present [10-12]. Hence, determining the factors that drive alpha and beta diversity patterns is crucial for conservation of biodiversity in coastal areas that are strongly affected by human activities and climate change.

Estuaries are important ecosystems, playing critical roles in conserving many migratory water birds, acting as a sink for pollutants, providing critical ecosystem services, and serving as nursery grounds. Community zonation in salt marshes has been attributed to differences in soil salinity and moisture [13,14], tidal inundation [15], flooding [16], and altitude [17]. Biotic factors, such as interspecific competition [18] and positive interactions [19] also play important roles in shaping patterns of biodiversity in salt marshes. The Yellow River Estuary (YRE) is a newly formed and fragile ecosystem comprising three estuarine zones. These young, neighboring estuaries provide contrasting environments to study how spatial and environmental processes affect species distribution. Much of the research on plant-environment relationships has been conducted on community or local scales [20-23]. As reported recently, however, niche and neutral processes are not mutually exclusive and can affect patterns of biodiversity simultaneously $[11,24]$. Analyses that do not take spatial autocorrelation into account will result in spurious associations between species composition and environmental factors, instead of revealing the true ones [7,25]. After analyzing the relationships between plant communities and abiotic factors in the YRE, Cui [26] suggested that spatial variations may affect plant distribution. Song [27] analyzed the environmental and spatial variation on a small scale. However, the intrinsic mechanisms accounting for species distribution patterns are still obscure [28].

Based on the understanding of factors driving diversity patterns, we hypothesized that both environmental and spatial variations play important roles in driving plant distribution patterns in the YRE. We explored this hypothesis by answering the following questions: (i) What are the relative contributions of spatial and environmental variables to plant species richness and composition? (ii) What is the relative contribution of each environmental factor to community species richness and composition patterns? (iii) Are plant species richness and composition affected differently with respect to the age of the estuary?

\section{Materials and methods}

\subsection{Study area}

The YRE nature reserve is located in Shandong Province, eastern China. This area has a temperate monsoon conti- nental climate. The area extends from $37^{\circ} 39^{\prime}$ to $38^{\circ} 16^{\prime} \mathrm{N}$ latitude and $118^{\circ} 31^{\prime}$ to $119^{\circ} 20^{\prime} \mathrm{E}$ longitude (Figure 1). The annual average temperature is $14^{\circ} \mathrm{C}$ and the mean annual precipitation is $600 \mathrm{~mm}$, but the potential evaporation is $1944 \mathrm{~mm}$. The elevation varies from 0 to $4 \mathrm{~m}$ above the sea level. Suaeda salsa and Phragmites australis are widely distributed herbaceous species.

The YRE nature reserve consists of two separate parts: the floodplains and the abandoned river mouth in the north (E1_D, approx. $500 \mathrm{~km}^{2}$ ) and the floodplains and the active river mouth in the east (E2_Q and E3_C, approx. $1050 \mathrm{~km}^{2}$ ). According to the flow processes of the Yellow River and the inflowing freshwater, the YRE can be divided into three zones (Figure 1): the Diaokou subestuary (E1_D in Figure 1) and the abandoned river mouth in the north, through which the Yellow River flowed before 1976; the Qingshui subestuary (E2_Q in Figure 1), through which the Yellow River flowed from 1976 to 1995 (this area has a relatively high sea level); and the Chahe subestuary (active river mouth, E3_C in Figure 1), where the Yellow River has flowed since 1996. E3_C is an estuarine marsh with many fresh water channels, and most of this area is affected by sediments and fresh water. The coastline has eroded in the E1_D and E2_Q subestuaries since the supply of fresh sediments stopped.

\subsection{Data collection}

The field survey was conducted from August to September, 2008. We established 309 plots $(1 \mathrm{~m} \times 1 \mathrm{~m})$ perpendicular to the coastline or the bank of the Yellow River (Figure 1). In each plot, we recorded the total number of each species.

The environmental matrix included soil salinity, soil

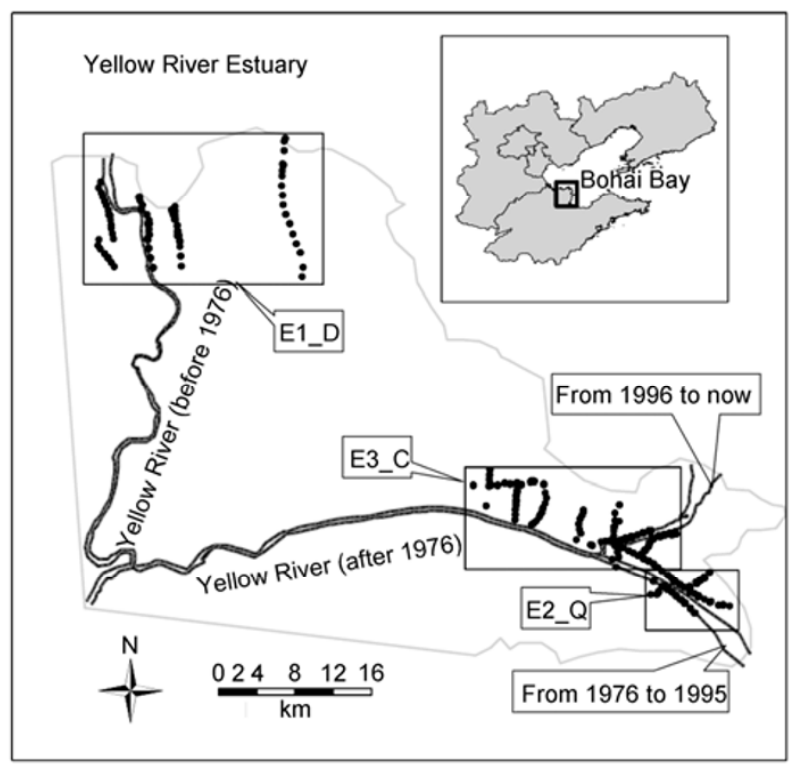

Figure 1 Map of Yellow River Estuary showing sampling area, flow process of Yellow River before and after 1976, and each subestuary included in this study. '’' represents locations of sampled plots. 
moisture, water table, groundwater electricity conductivity, elevation, curvature, soil type, soil texture, geomorphology, macro-relief, and distance from the coastline and the river. Elevation and curvature data were derived from a digital elevation model (1:50000) provided by the National Geomatics Center of China.

At each plot, we measured soil electrical conductivity (soil salinity) with a portable conductivity meter (Field Scout Soil EC 110 Meter, Spectrum Technologies, Plainfield, IL, USA), and soil moisture with a portable time-domain reflectometer (TRIME-EZ/EZ, TRIME-IT, IMKO, Ettlingen, Germany) in the top soil layer (to $15-\mathrm{cm}$ depth).

Data for the depth to the water table and electrical conductivity of the groundwater were obtained from an existing database. From 2004 to 2005, the depth to the water table and electrical conductivity of the groundwater were investigated 122 times in each well of the 18 groundwater monitoring sites (provided by http://www.geodata.cn). We generated 122 groundwater electrical conductivity and groundwater depth surface maps from groundwater data, then derived plot groundwater depth and electrical conductivity values from the maps. The mean, all-time recorded minimum, and all-time recorded maximum values of each plot were derived.

To characterize the effects of the river and the sea, we obtained the perpendicular distance in meters from the shore and the river for each plot. The shoreline was derived from Landsat 7 enhanced thematic mapper plus (ETM+) images (Sept. 13, 2008), and some main tidal creeks were also mapped. We obtained the geographic coordinates for each plot with a global positioning system (Explorist 400 GPS, Magellan, Gladesville, Australia). The spatial matrix included data derived from geographic coordinates.

Geomorphology and soil-type data were obtained from additional input lithology maps (1:10000 with 30 -m grid size), and soil texture and micro-relief data were collected from field surveys. All of these data were converted to dummy variables. We compiled data on the physical environment and history of each plot from field-recorded measures and through overlay of plot locations with mapped features in a geographic information system (GIS) (ARC/INFO software, version 9.2; Environmental Systems Research Institute (ESRI)). We divided the area into five geographic subregions, based primarily on physiography, including embankments, marshes, depressions, abandoned, present. We grouped the soil texture into three generalized types; loam, sandy clay, and clay. The soil types were gleyic and fluvisols.

\subsection{Data analyses}

Rare species (absence $\leqslant 2$ ) were removed before analyses. The species abundance matrix was transformed using the Hellinger transformation [29]. We estimated alpha diversity (species richness) as the number of species sampled in a field plot. Beta diversity was quantified with the Bray-Curtis dissimilarity index [30,31]. To assess the affinities of species to different estuaries, we performed indicator species analysis [32] on species abundance data.

We considered two types of variables: (a) environmental and (b) spatial. We selected the following options for the environment matrix analysis: (i) all edaphic variables were standardized; (ii) we used data for soil salinity, soil moisture, groundwater electricity conductivity, water table, distance from river and sea, altitude, and convexity to construct third-degree polynomial equations, the monomials with exponents allowed modeling of nonlinear relationships between environmental factors and response variables; (iii) environmental variables were transformed to give approximately normal distributions when necessary.

To understand the mechanisms generating spatial structures in communities, the spatial structures of the samples were modeled using principal coordinates of neighboring matrices (PCNM) analysis [33]. This method is well-suited for detection of multi-scale spatial structures. First, the spatial coordinates of each sampling site were used to build a Euclidean distance matrix. Then, the matrix was truncated at the smallest distance that kept all sites connected in a single network, which corresponded to the maximum distance between two successive sampling sites in onedimensional studies. The truncated portion was filled with an arbitrarily large distance value. Then, a principal coordinate analysis was carried out, and the eigenvectors associated with positive eigenvalues were retained as spatial variables (PCNM variables). These could be computed for regular or irregular sets of points in space or time. To identify the contribution of specific environmental factors and spatial variables, the unique and shared explanatory power of both variables were disentangled using variation partitioning [3,34]. Partitioning was carried out through a series of partial redundancy analyses (pRDA). pRDA have been used to partition the variance of species abundance data matrices into multiple components, including a pure environmental component, a pure spatial component, a spatially structured environmental component, and residual variation (see Borcard et al. [3] for details).

Forward selection [35] was performed separately for each set of environmental and spatial explanatory variables, to select those variables making a significant $(P \leqslant 0.05$ after 999 random permutations) contribution to explaining variation in plant composition and richness. Only the selected variables were used in variation partitioning. Adjusted bi-multivariate redundancy statistics were computed. The $R^{2}$ values were adjusted $\left(R_{\mathrm{a}}^{2}\right)$ to account for the number of sampling sites and explanatory variables, as the $R_{\text {a }}^{2}$ statistics were unbiased estimates of the contribution of the independent variables to explaining the response variables [36]. Monte Carlo permutation tests (9999 permutations) were used to compute the significances of the different compo- 
nents.

We investigated the importance of each explanatory variable using RDAs with each variable as the only explanatory variable. Because of the differences in the lack-of-fit data to the response models for different multivariate data sets, the unexplained variation and hence the 'total variation explained' by all factors were generally inappropriate to compare data sets [37]. To overcome this problem, we focused on the explainable variation only, using the 'proportions of total variation explained' by the particular sets of environmental variables instead.

All the analyses were performed in the R-language environment (version 2.9, R Foundation for Statistical Computing, Vienna, Austria), using the packages 'vegan' [38], 'PCNM', and 'packfor'.

\section{Results}

\subsection{Species distribution pattern}

In total, there were 31 plant species in the 309 sample plots in the YRE (Table 1). All of them were native species. The main species are listed in Table 2. The two dominant species were $S$. salsa and $P$. australis, and one or both were present in 269 of the 309 plots. The frequencies of other species were relatively low. The total number of species in the estuaries varied from 15 in E2_Q to 27 in E3_C (Table 1). The means of species richness $(\alpha)$ were similar among the different estuaries, whereas the mean dissimilarity in the E1_D was much lower than that in both E2_Q and E3_C.

The indicator species differed among the three subestuaries (Figure 2). Besides $S$. salsa, the main indicator species

Table 1 Information for each estuary. Data are mean values \pm standard errors

\begin{tabular}{|c|c|c|c|c|}
\hline & All & E1_D & E2_Q & E3_C \\
\hline Number of sites & 309 & 79 & 75 & 155 \\
\hline Species richness throughout area & 31 & 17 & 15 & 27 \\
\hline Mean of site species richness & $2.55 \pm 0.11$ & $2.69 \pm 0.21$ & $2.43 \pm 0.17$ & $2.54 \pm 0.16$ \\
\hline Mean of site Bray-Curtis dissimilarity & $0.85 \pm 0.01$ & $0.75 \pm 0.03$ & $0.85 \pm 0.03$ & $0.86 \pm 0.02$ \\
\hline Mean of soil salinity $\left(\mathrm{ms} \mathrm{cm}^{-1}\right)$ & $6.7 \pm 0.3$ & $8.2 \pm 0.6$ & $5.7 \pm 0.4$ & $6.2 \pm 0.3$ \\
\hline Mean of soil moisture (\%) & $42.9 \pm 0.7$ & $36.65 \pm 1.6$ & $44.3 \pm 1.6$ & $45.1 \pm 0.8$ \\
\hline
\end{tabular}

Table 2 Relative frequency of herbaceous species in each subestuary. Species with relative frequency $>5$ are shown. Species codes correspond to those shown in Figure 2

\begin{tabular}{|c|c|c|c|c|}
\hline Species & Code & E1_D & E2_Q & E3_C \\
\hline Suaeda salsa & Ss & 87 & 44 & 52 \\
\hline Phragmites australis & $\mathrm{Pa}$ & 53 & 64 & 58 \\
\hline Apocynum venetum & Av & 4 & 32 & 10 \\
\hline Triarrhena sacchariflora & TS & 0 & 31 & 10 \\
\hline Metaplexis japonica & $\mathrm{Mj}$ & 22 & 15 & 6 \\
\hline Imperata cylindrica & Ic & 6 & 20 & 11 \\
\hline Glycine soja & Gs & 1 & 8 & 12 \\
\hline Sonchus brachyotus & $\mathrm{Sb}$ & 10 & 7 & 7 \\
\hline Limoninum sinense & Ls & 18 & 0 & 3 \\
\hline Typha orientalis & To & 0 & 1 & 11 \\
\hline Aeluropus littoralis & $\mathrm{Al}$ & 18 & 1 & 0 \\
\hline Aster subulatus & As & 5 & 0 & 6 \\
\hline Cirsium setosum & $\mathrm{Csm}$ & 0 & 9 & 3 \\
\hline Scorzonera mongolica & $\mathrm{Sa}$ & 13 & 0 & 0 \\
\hline Cyperus glomeratus & $\mathrm{Cg}$ & 0 & 0 & 6 \\
\hline Cyperus michelianus & $\mathrm{Cm}$ & 0 & 0 & 5 \\
\hline Potentilla supina & Ps & 0 & 0 & 5 \\
\hline Cirsium segetum & Cs & 0 & 0 & 5 \\
\hline Artemisia capillaris & Ac & 9 & 0 & 0 \\
\hline Eclipta prostrata & Ep & 0 & 0 & 5 \\
\hline Polygonum hydropiper & $\mathrm{Ph}$ & 0 & 0 & 5 \\
\hline
\end{tabular}




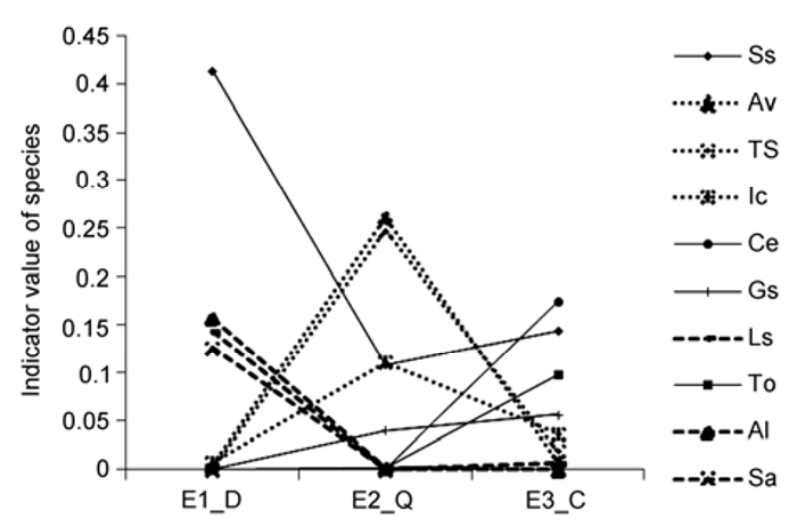

Figure 2 Indicator value of main species in different subestuaries. Species names are abbreviated using codes given in Table 2.

in E1_D were Aeluropus littoralis, Limoninum sinense, and Socorzonera austriaca. Those in E2_Q were Apocynum venetum, Triarrhena sacchariflora, and Imperata cylindrica, and those in E3_C were Calamagrostis epigeios and Typha orientalis. The indicator values of C. epigeios, T. orientalis, and Glycine soja decreased, while those of Metaplexis japonica, L. sinense, A. littoralis, and Scorzonera mongolica increased with estuary age.

\subsection{Variation partitioning on spatial and environmen- tal factors}

In the YRE, 29.9\% (fraction env and spa+env, All; Figure 3) of the variation in species composition was explained by environmental factors and $15 \%$ (fraction spa and spa+env, All; Figure 3) was explained by spatial variables. The total variation explained (TVE) comprised 31.1\% (All; Figure 2) of the total inertia of species composition in the YRE. The pure environmental variables explained the largest fraction (51.9\%, fraction env, All; Figure 3 ) of the TVE. The effect of pure spatial factors explained $4.2 \%$ of the TVE (fraction spa, All; Figure 3) and that of the covariation between environmental and spatial factors explained $43.9 \%$ (fraction spa+env, All; Figure 3). The total amount of variation ex-

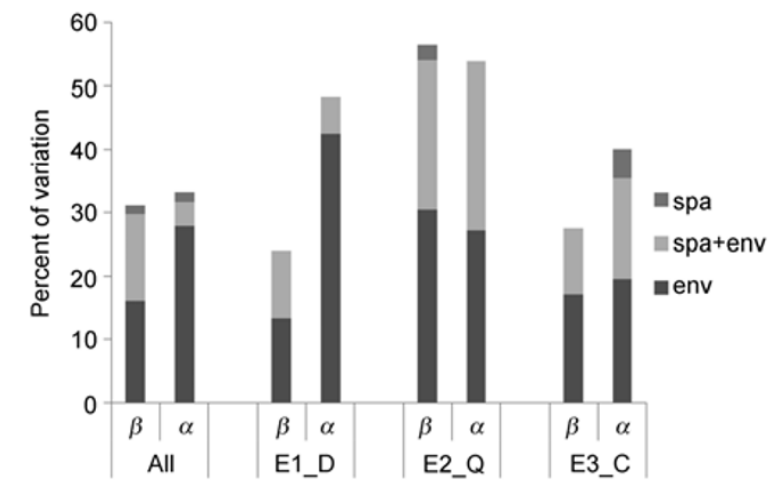

Figure 3 Variation partitioning for species composition $(\beta)$ and species richness $(\alpha)$. env, Environment; spa+env, environment+spatial; spa, spatial. All, results were obtained by analyzing three estuaries together.

plained differed among the three subestuaries. The TVE of species richness ranged from $40 \%$ (in E3_C) to 55\% (in E2_Q), while the TVE of species composition ranged from $27.7 \%$ (in E1_D) to $56.5 \%$ (in E2_Q).

In each subestuary, more than $95 \%$ of the TVE for community composition was explained by the environment. Pure environmental variables explained the largest fraction (more than 50\%) of the TVE compared with the effect of pure spatial factors (4.2\% in YRE and E2_Q, and not significant in E1_D and E3_C). The remaining TVE was explained by the covariation effect of environmental and spatial factors (ranging from $30 \%$ to $44 \%$ ). Almost $90 \%$ of the TVE for species richness in the different subestuaries could be explained by the environment.

\subsection{Relative contribution of environmental compo- nents}

The forward selection procedure identified different numbers of environmental variables as significant predictors of variation in species richness and composition (Table 3). The forward selection retained less factors than the significant test (Table 4), indicating that most of the environmental

Table 3 Environmental variables retained after forward selection procedure ${ }^{\text {a) }}$

\begin{tabular}{|c|c|c|c|c|c|c|c|c|}
\hline \multirow[b]{2}{*}{ Estuary } & \multicolumn{4}{|c|}{ Species composition } & \multicolumn{4}{|c|}{ Richness } \\
\hline & All & E1_D & E2_Q & E3_C & All & E1_D & E2_Q & E3_C \\
\hline Salinity & $\mathrm{T}$ & $\mathrm{T}$ & $\mathrm{T}$ & $\mathrm{T}$ & $\mathrm{T}$ & $\mathrm{T}$ & & \\
\hline Moisture & $\mathrm{T}$ & - & $\mathrm{T}$ & $\mathrm{T}$ & $\mathrm{T}$ & & $\mathrm{T}$ & $\mathrm{T}$ \\
\hline Groundwater table & & $\mathrm{T}$ & $\mathrm{T}$ & & - & - & & - \\
\hline Groundwater_ec & & & & & - & - & $\mathrm{T}$ & - \\
\hline Geomorphology & $\mathrm{T}$ & & & $\mathrm{T}$ & & - & & $\mathrm{T}$ \\
\hline Soil type & & $\mathrm{T}$ & - & - & - & & - & - \\
\hline Soil texture & & & - & - & - & - & - & \\
\hline Distance from sea & $\mathrm{T}$ & & $\mathrm{T}$ & $\mathrm{T}$ & $\mathrm{T}$ & - & - & $\mathrm{T}$ \\
\hline Distance from river & $\mathrm{T}$ & - & $\mathrm{T}$ & & - & - & - & \\
\hline
\end{tabular}

a) "T" represents environmental factor retained after forward selection. "-" represents environmental factors that were not significant for species composition or richness $(a \leqslant 0.05,9999)$. Groundwater_ec, groundwater electricity conductivity. All, results were obtained by analyzing three estuaries together. 
Table 4 Ability of unique environmental factors $(\%)$ to explain variations in species composition $(\beta)$ and species richness $(\alpha)^{\text {a) }}$

\begin{tabular}{|c|c|c|c|c|c|c|c|c|}
\hline \multirow[b]{2}{*}{ Esturay } & \multicolumn{4}{|c|}{ Species composition } & \multicolumn{4}{|c|}{ Richness } \\
\hline & All & E1_D & E2_Q & E3_C & All & E1_D & E2_Q & E3_C \\
\hline Salinity & 65.5 & 73.8 & 60.2 & 78.1 & 55.5 & 98.8 & 30.7 & 37.2 \\
\hline Moisture & 11.6 & - & 46.8 & 40.9 & 61.3 & 7.8 & 96.1 & 66.8 \\
\hline Groundwater table & 22.2 & 32.9 & 20.9 & 23.4 & - & - & 28.5 & - \\
\hline Groundwater_ec & 21.2 & 56.7 & 21.1 & 27.0 & - & - & 25.7 & - \\
\hline Geomorphology & 25.4 & 25.0 & 24.1 & 34.7 & 37.0 & - & 90.7 & 31.2 \\
\hline Micro-relief & 14.8 & 27.9 & 29.0 & - & 5.5 & - & 71.1 & - \\
\hline Soil type & 5.1 & 7.1 & - & - & - & 7.2 & - & - \\
\hline Soil texture & 11.9 & 12.5 & - & - & - & - & - & 4.7 \\
\hline Distance from sea & 3.2 & 12.5 & 2.8 & 13.1 & 11.3 & - & - & 49.1 \\
\hline Distance from river & 18.3 & - & 15.1 & 19.7 & - & - & - & 16.5 \\
\hline
\end{tabular}

a) "-"represents environmental factors that were not significant for species composition or richness $(a \leqslant 0.05,9999)$. Groundwater_ec, groundwater electricity conductivity. All, results were obtained by analyzing three estuaries together.

factors were correlated. The environmental factors that controlled species composition differed from those controlling species richness. Soil salinity and soil moisture were retained in most of the models, and distance from sea and river and geomorphology were also popular (Table 3). By further dissecting the variation explained by the environmental component, we found that the unique contributions of salinity (maximum value of TVE was $98.8 \%$ in E1_D), moisture (maximum value of TVE was $96.1 \%$ in E2_Q) and geomorphology (maximum value of TVE was $90.7 \%$ in E2_Q) affected species composition and richness more strongly than other factors did. In E1_D, species richness was controlled by soil salinity (TVE $=98.8 \%$ ). In E2_Q, soil moisture (96.1\% of TVE) and geomorphology (90.7\% of TVE) were the most important environmental variables affecting species richness. In E3_C, both soil moisture $(66.8 \%$ of TVE) and distance to sea (49.1\% of TVE) were important factors. Although the factors influencing species composition differed among the three subestuaries (Table 4), salinity contributed most to TVE in species composition (65.5\% in YRE, $73.7 \%$ in E1_D, 60.2\% in E2_Q, 78.1\% in E3_C). Other factors had comparatively small effects on species richness and composition.

\section{Discussion}

\subsection{Do spatial processes or environment structure the pattern of diversity?}

Our models showed the influence of environment, spatial processes, and their combined effects on plant species richness and composition in the YRE. The results support our hypothesis that these factors act simultaneously at a regional scale. In contrast to pure spatial variation, environmental variation was more strongly associated with plant community composition and species richness.

Because of the dominant contribution of the environment in all estuaries, our results suggest that the niche process was the main process affecting species composition and richness. Among the environmental factors, our analyses confirmed the important roles of soil salinity and moisture as local factors shaping the structure of the plant community. These results were consistent with other observations in salt marshes [27,39]. Because geomorphology and distance from the sea and river were always retained after forward selection (Table 3), we suggest that these factors also played important roles in the structure and organization of plant communities by dictating the roles of other factors that affect the distribution and abundance of plants in marsh habitats. Several studies have shown many factors vary along with offshore distance, such as organic carbon content, total phosphorus and total nitrogen [40], tidal frequency [41], and $\mathrm{pH}$ [42].

Recognizing the important role of the niche process (environment) in influencing species composition and richness does not necessarily imply that spatial processes were not important in the YRE, or that they were not mutually exclusive. The covariation between environment and space makes it difficult to discriminate between niche processes and other spatial processes $[8,43]$. The spatial structure, in particular the purely spatial fraction, likely reflects historical processes [10], notably dispersal limitation [8], biotic processes, and unmeasured underlying processes [3] in structuring the patterns of diversity. In the YRE, sudden changes resulting from floods and storms can remove large parts of habitats, which can hamper species recolonization because of the damage to parent plants and seed banks. For organisms to survive, grow, and reproduce in a region in which they were previously absent, they first must be able to disperse into the region, and then would be subject to niche-based processes to establish their growth site. Thus, both dispersal limitation and environmental determinism play roles in shaping the distribution of species [27]. The relative importance of niche processes and spatial processes may change on spatial and temporal scales. Spatial autocorrelation has been noted previously in the Everglades [44]; in 
that study, spatial proximity accounted for significant variations in vegetation patterns.

A relatively large proportion $(43 \%-75 \%)$ of community variation was not explained by any of the environmental variables or spatial data. The large percentage of unexplained variance is a common finding in ordination models of plant communities [37]. There are several possible reasons for this high proportion of unaccounted variation, for example, the characteristics of RDA and our data, random dispersal, disturbance, other factors that were not measured in the field, biological processes [45], or unmeasured non-spatial explanatory variables, such as temporal changes in salinity and water environment gradients [46], rain [47], and flooding [16], which influence the moisture and salinity of the region at different times. The spatial and temporal variations in soil salinity are critical aspects of salt marsh ecology [48]. Biotic factors, such as between-species competition [49,50] and positive relationships [19,22], may be particularly important.

\subsection{Which environmental factors are dominant factors in species composition and richness variation?}

Our study suggested that salinity was the dominant factor affecting the abundance and composition of plant species in the YRE. This result is consistent with those reported in many other studies on salt marshes, such as a wetland near the YRE [51] and other coastal sites [52]. In all studied areas of the YRE, soil moisture and soil salinity were both important factors affecting species richness, but salinity was the dominant factor in E1_D, and soil moisture was the dominant factor in E2_Q and E3_C. Many researchers have also shown that soil moisture affects species richness in salt marshes [53,54].

Species composition is a less synthetic description of sites than richness in terms of environmental variations. The main factors affecting species composition and richness may differ, because different species are favored by different environmental conditions and different dispersal mechanisms. Our results suggested that the amount of explained variation (except in E2_Q) captured by all statistically significant explanatory variables was higher for species richness data than for species composition data. These findings agree with the conclusions of Ozinga et al. [55], who noted that species composition is more difficult to explain than species richness as this requires specific knowledge of the nature of each species.

\subsection{Why were the diversity patterns different among the three subestuaries?}

The percentage of variation explained by various factors differed among the subestuaries. This illustrated that the relative importance of niche and neutral processes was also dependent on the geographic extent of the study [56]. The relative importance of factors differed among the subestuaries, and this may have been because of differences in climate [57], geography [58], geographical age, and size. The geographical age differed among the subestuaries, and this affected the structure of the physical habitat, which was the major source of variation in species richness and composition. Environmental factors dominated species composition and richness in the YRE, including all three subestuaries. This finding indicated that species richness and species composition were constrained by environmental factors, both on a small scale (e.g., within subestuary E3_C) and on a large scale (e.g., within the entire YRE). All the estuaries had a common indicator species, S. salsa. However, many species (C. epigeios, S. mongolica, and Cyperus glomeratus) were found only in one estuary, even though the estuaries had the same soil parent material. This may have been because of differences in age, position, environment, and habitat preferences of species among the subestuaries. The variations in species composition among the estuaries implied a succession process from the new estuary (E3_C) to the old estuary (E1_D).

E3_C estuary: E3_C is frequently affected by both the river and the sea, and it contains many fresh water channels. This makes it a complex environment that changes rapidly over time. The high levels of fresh water in the saline soils ameliorated salt stress and promoted plant development, compared with soils with low moisture content. This result is consistent with the higher species richness in E3_C, which was associated with a high number of specialist species such as $C$. glomeratus, C. michelianus, Potentilla supine, and Polygonum hydropiper, which were only distributed around the riverbank.

E1_D estuary: The E1_D subestuary was affected by the sea tide. There were no fresh water inputs, and so the area was dominated by the saline environment. The combined effects of soil moisture and salinity restricted species distribution. Generalist species (i.e., S. salsa and P. australis) are likely to be adapted to the low moisture and highly saline environment. A unique assemblage of $S$. salsa and $P$. australis was found at most of the sites within the subestuary; consequently, this subestuary had the lowest dissimilarity among sites. Some species (Setaria viridis, Artemisia capillaries, and Artemisia carvifolia) that were always distributed in upland areas were also found in the low-salinity area of E1_D. These species represented a more advanced stage of natural succession in the YRE.

E2_Q estuary: Most of the land area in E2_Q had a higher topographic position than that in the other subestuaries because of accumulation of sediments. The geomorphic structure of E2_Q directly controlled the submergence/emergence ratio at any site through its interaction with the sea tide, hydrology, and flooding. That, in turn, influenced other factors such as soil salinity, waterlogging, and moisture, all of which affected the distribution of various plant species within the marsh. Species such as A. venetum, 
T. sacchariflora, and I. cylindrica were more likely to be specialized to the stable environment in E2_Q. All of the species found in E2_Q were also found in E1_D or E3_C, confirming the transitional status of E2_Q. Because E2_Q was at the middle stage of succession, it showed lower species richness than the other two estuaries, and the median beta diversity was smaller than that of E3_C. This diversity pattern might reflect the low heterogeneity environment, and separates this subestuary from the upland in E2_Q.

\section{Conclusion}

This study represents systematic quantification of factors across a large, contiguous region of the YRE based on field plot data. Our results suggested that composition and richness patterns of plant species in the YRE are strongly controlled by the environment, while the contribution of spatial processes is relatively small. Soil salinity was the dominant factor controlling species composition, and soil moisture was the dominant factor affecting species richness in E2_Q and E3_C. Soil salinity was the most important factor affecting species richness in E1_D. Geomorphology and the distance from sea and river also played important roles in species composition. The common environmental factors (influence of the sea) and different factors (e.g., the different histories of river flow in each subestuary) and the habitat preferences of each species led to differences in patterns of diversity among the different subestuaries.

\section{Abbreviations}

$\begin{array}{ll}\text { E1_D } & \text { Diaokou subestuary } \\ \text { E2_Q } & \text { Qingshui subestuary } \\ \text { E3_C } & \text { Chahe subestuary } \\ \text { PCNM } & \text { principal coordinates of neighboring matrices } \\ \text { RDA } & \text { redundancy analysis } \\ \text { TVE } & \text { total variation explained } \\ \text { YRE } & \text { Yellow River Estuary }\end{array}$

This work was supported by National Science \& Technology Pillar in the 11th Five-Year Program (Grant No. 2006BAC01A13). Additional support for field work was provided by the Yellow River Delta Research Center, Binzhou University, and by the Administration Bureau of the Yellow River Delta Nature Reserve. Groundwater depth and electrical conductivity data were provided by http://www.geodata.cn.

1 Hooper D U, Vitousek P M. The effects of plant composition and diversity on ecosystem processes. Science, 1997, 277: 1302-1305

2 Jassby A D, Kimmerer W J, Monismith S G, et al. Isohaline position as a habitat indicator for estuarine populations. Ecol Appl, 1995, 5: 272-289

3 Borcard D, Legendre P, Drapeau P. Partialling out the spatial component of ecological variation. Ecology, 1992, 73: 1045-1055

4 Qian H, Ricklefs R E. A latitudinal gradient in large-scale beta diver- sity for vascular plants in North America. Ecol Lett, 2007, 10: 737-744

5 Qian H, Badgley C, Fox D L. The latitudinal gradient of beta diversity in relation to climate and topography for mammals in North America. Global Ecol Biogeogr, 2009, 18: 111-122

6 Wright S J. Plant diversity in tropical forests: a review of mechanisms of species coexistence. Oecologia, 2002, 130: 1-14

7 Legendre P. Spatial autocorrelation - trouble or new paradigm. Ecology, 1993, 74: 1659-1673

8 Gilbert B, Lechowicz M J. Neutrality, niches, and dispersal in a temperate forest understory. Proc Nat Acad Sci USA, 2004, 101: 7651-7656

9 Hubbell S P. The Unified Neutral Theory of Biodiversity and Biogeography. Princeton: Princeton University Press, 2001

10 Svenning J C, Skov F. The relative roles of environment and history as controls of tree species composition and richness in Europe. J Biogeogr, 2005, 32: 1019-1033

11 Legendre P, Mi X C, Ren H B, et al. Partitioning beta diversity in a subtropical broad-leaved forest of China. Ecology, 2009, 90: 663-674

12 Smith T W, Lundholm J T. Variation partitioning as a tool to distinguish between niche and neutral processes. Ecography, 2010, 33: 648-655

13 Crain C M, Silliman B R, Bertness S L, et al. Physical and biotic drivers of plant distribution across estuarine salinity gradients. Ecology, 2004, 85: 2539-2549

14 Egan T P, Ungar I A. Similarity between seed banks and above-ground vegetation along a salinity gradient. J Veg Sci, 2000, 11: 189-194

15 Silvestri S, Defina A, Marani M. Tidal regime, salinity and salt marsh plant zonation. Estuar Coast Shelf Sci, 2005, 62: 119-130

16 Pennings S C, Grant M B, Bertness M D. Plant zonation in low-latitude salt marshes: disentangling the roles of flooding, salinity and competition. J Ecol, 2005, 93: 159-167

17 Sanchez J M, Izco J, Medrano M. Relationships between vegetation zonation and altitude in a salt-marsh system in northwest Spain. J Veg Sci, 1996, 7: 695-702

18 Pennings S C, Callaway R M. Salt-marsh plant zonation-the relative importance of competition and physical factors. Ecology, 1992, 73: 681-690

19 Bertness M D, Callaway R. Positive Interactions in Communities. Trend Ecol Evolut, 1994, 9: 191-193

20 Zhao K F, Feng L T, Zhang S Q. Study on the salinity-adaptation physiology in different ecotypes of Phragmites australis in the Yellow River Delta of China: Osmotica and their contribution to the osmotic adjustment. Estuar Coast Shelf Sci, 1999, 49: 37-42

21 Cui B, Zhao X, Yang Z, et al. Response of reed community to the environment gradient-water depth in the Yellow River Delta, China. Front Biol China, 2008, 3: 194-202

22 He Q, Cui B, An Y. The importance of facilitation in the zonation of shrubs along a coastal salinity gradient. J Veg Sci, 2011, 22: 828-836

23 Fan X, Pedroli B, Liu G, et al. Potential plant species distribution in the Yellow River Delta under the influence of groundwater level and soil salinity. Ecohydrology, 2011, 4: 744-756

24 Qian H, Ricklefs R E. Disentangling the effects of geographic distance and environmental dissimilarity on global patterns of species turnover. Global Ecol Biogeogr, 2012, 21: 341-351

25 Keitt T H, Bjornstad O N, Dixon P M, et al. Accounting for spatial pattern when modeling organism-environment interactions. Ecography, 2002, 25: 616-625

26 Cui B S, He Q, An Y. Community structure and abiotic determinants of salt marsh plant zonation vary across topographic gradients. Estuaries Coasts, 2011, 34: 459-469

27 Song C Y, Huan L G, Liu Q S. Spatial and environmental effects on plant communities in the Yellow River Delta, eastern China. J Forest Res, 2009, 20: 117-122

28 Li F, Xie Y, Chen X, et al. Plant distribution can be reflected by physiological responses to salinity of three submerged macrophytes 
from the Modern Yellow River Delta. Fund Appl Limnol, 2011, 179: 159-167

29 Legendre P, Gallagher E D. Ecologically meaningful transformations for ordination of species data. Oecologia, 2001, 129: 271-280

30 Faith D P, Minchin P R, Belbin L. Compositional dissimilarity as a robust measure of ecological distance. Vegetatio, 1987, 69: 57-68

31 Bray J R, Curtis J T. An ordination of the upland forest communities of southern Wisconsin. Ecol Monogr, 1957, 27: 326-349

32 Dufrene M, Legendre P. Species assemblages and indicator species: The need for a flexible asymmetrical approach. Ecol Monogr, 1997, 67: $345-366$

33 Borcard D, Legendre P. All-scale spatial analysis of ecological data by means of principal coordinates of neighbour matrices. Ecol Model, 2002, 153: 51-68

34 Okland R H. Partitioning the variation in a plot-by-species data matrix that is related to $\mathrm{n}$ sets of explanatory variables. J Veg Sci, 2003, 14: 693-700

35 Blanchet F G, Legendre P, Borcard D. Forward selection of explanatory variables. Ecology, 2008, 89: 2623-2632

36 Peres-Neto P R, Legendre P, Dray S, et al. Variation partitioning of species data matrices: Estimation and comparison of fractions. Ecology, 2006, 87: 2614-2625

37 Okland R $\mathrm{H}$. On the variation explained by ordination and constrained ordination axes. J Veg Sci, 1999, 10: 131-136

38 Oksanen J, Kindt R, Legendre P, et al. Vegan: Community Ecology Package. version 115-4: R Foundation for Statistical Computing, 2009

39 Noe G B. Temporal variability matters: Effects of constant vs. varying moisture and salinity on germination. Ecol Monogr, 2002, 72: $427-443$

40 Teodoru C R, Friedl G, Friedrich J, et al. Spatial distribution and recent changes in carbon, nitrogen and phosphorus accumulation in sediments of the Black Sea. Mar Chem, 2007, 105: 52-69

41 Christiansen T, Wiberg P L, Milligan T G. Flow and sediment transport on a tidal salt marsh surface. Estuar Coast Shelf Sci, 2000, 50: $315-331$

42 Chaouti A, Colombini I, Fallaci M, et al. Structure and distribution of the benthic macrofauna on a Northwest African sandy beach close to a freshwater river discharge. Mar Ecol-Evol Persp, 2008, 29: 99-107

43 Bell G, Lechowicz M J, Waterway M J. The comparative evidence relating to functional and neutral interpretations of biological communities. Ecology, 2006, 87: 1378-1386
44 King R S, Richardson C J, Urban D L, et al. Spatial dependency of vegetation-environment linkages in an anthropogenically influenced wetland ecosystem. Ecosystems, 2004, 7: 75-97

45 Legendre P, Legendre L. Numerical Ecology. 2nd ed. Amsterdam: Elsevier Science B.V., 1998

46 Rogel J A, Silla R O, Ariza F A. Edaphic characterization and soil ionic composition influencing plant zonation in a semiarid Mediterranean salt marsh. Geoderma, 2001, 99: 81-98

47 Noe G B, Zedler J B. Variable rainfall limits the germination of upper intertidal marsh plants in southern California. Estuaries, 2001, 24: $30-40$

48 Wang H, Hsieh Y P, Harwell M A, et al. Modeling soil salinity distribution along topographic gradients in tidal salt marshes in Atlantic and Gulf coastal regions. Ecol Model, 2007, 201: 429-439

49 Callaway R M, Walker L R. Competition and facilitation: A synthetic approach to interactions in plant communities. Ecology, 1997, 78: 1958-1965

50 Cui B, He Q, Zhang K, et al. Determinants of annual-perennial plant zonation across a salt-fresh marsh interface: a multistage assessment. Oecologia, 2011, 166: 1067-1075

51 Li W Q, Liu X J, Khan M A, et al. Relationship between soil characteristics and halophytic vegetation in coastal region of North China. Pakistan J Bot, 2008, 40: 1081-1090

52 Bouzille J B, Kerneis E, Bonis A, et al. Vegetation and ecological gradients in abandoned salt pans in western France. J Veg Sci, 2001, 12: $269-278$

53 Shaltout K H, Elkady H F, Alsodany Y M. Vegetation analysis of the Mediterranean region of Nile-Delta. Vegetatio, 1995, 116: 73-83

54 Bornman T G, Adams J B, Bate G C. Environmental factors controlling the vegetation zonation patterns and distribution of vegetation types in the Olifants Estuary, South Africa. S Afr J Bot, 2008, 74: 685-695

55 Ozinga W A, Schaminee J H J, Bekker R M, et al. Predictability of plant species composition from environmental conditions is constrained by dispersal limitation. Oikos, 2005, 108: 555-561

56 Steinitz O, Heller J, Tsoar A, et al. Environment, dispersal and patterns of species similarity. J Biogeogr, 2006, 33: 1044-1054

57 Bertness M D, Pennings S C. Spatial Variation in Process and Pattern in Salt Marsh Plant Communities in Eastern North America. Dordrecht: Kluwer Academic Publishers, 2000

58 Ewanchuk P J, Bertness M D. Structure and organization of a northern New England salt marsh plant community. J Ecol, 2004, 92: $72-85$

Open Access This article is distributed under the terms of the Creative Commons Attribution License which permits any use, distribution, and reproduction in any medium, provided the original author(s) and source are credited. 